\title{
Repositioning of amprenavir as a novel extracellular signal-regulated kinase- 2 inhibitor and apoptosis inducer in MCF-7 human breast cancer
}

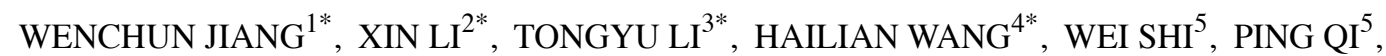 \\ CHUNYANG $\mathrm{LI}^{2}, \mathrm{JIE} \mathrm{CHEN}^{4}, \mathrm{JINKU} \mathrm{BAO}^{2}$, GUODONG HUANG $^{3}$ and $\mathrm{YI} \mathrm{WANG}^{4}$ \\ ${ }^{1}$ Nursing Department, Sichuan Academy of Medical Science and Sichuan Provincial People's Hospital, \\ Chengdu, Sichuan 610072; ${ }^{2}$ School of Life Sciences, Sichuan University, Chengdu, Sichuan 610065; \\ ${ }^{3}$ Center for Nephropathy, Ruikang Hospital Affiliated to Guangxi University of Chinese Medicine, Nanning, Guangxi 530011; \\ ${ }^{4}$ Center for Organ Transplantation, ${ }^{5}$ Department of Pediatrics, Sichuan Academy of Medical Science and \\ Sichuan Provincial People's Hospital, Chengdu, Sichuan 610072, P.R. China
}

Received October 25, 2016; Accepted December 5, 2016

DOI: $10.3892 /$ ijo.2017.3860

\begin{abstract}
Computational drug repositioning by virtually screening existing drugs for additional therapeutic usage could efficiently accelerate anticancer drug discovery. Herein, a library of 1447 Food and Drug Administration (FDA)approved small molecule drugs was screened in silico for inhibitors of extracellular signal-regulated kinase 2 (ERK2). Then, in vitro kinase assay demonstrated amprenavir, a HIV-1 protease inhibitor, as a potential kinase inhibitor of ERK2. The in vivo kinase assay indicated that amprenavir could inhibit ERK2-mediated phosphorylation of Bim $\mathrm{EL}_{\mathrm{L}}$ at Ser69. Amprenavir could suppress this phosphorylation in MCF-7 cells, which may further facilitate the association of $\mathrm{Bim}_{\mathrm{EL}}$ with several pro-survival molecules. Additionally, inhibition of ERK2-Bim ${ }_{\mathrm{EL}}$ signaling pathway by amprenavir could contribute to its anti-proliferative and apoptosis-inducing activity in MCF-7 cells. Finally, in vivo tumor growth and immunohistochemical studies confirmed that amprenavir remarkably suppressed tumor proliferation and induce apoptosis in MCF-7 xenografts. Taken together, amprenavir can effectively inhibit the kinase activity of ERK2, and thus
\end{abstract}

Correspondence to: Dr Yi Wang, Center for Organ Transplantation, Sichuan Academy of Medical Science and Sichuan Provincial People's Hospital, 32 West Ring Road, Chengdu, Sichuan 610072, P.R. China E-mail: w_yi@yahoo.com

Dr Jinku Bao, School of Life Sciences, Sichuan University, 19 Wangjiang Road, Chengdu, Sichuan 610065, P.R. China

E-mail: jinkubao@163.com

"Contributed equally

Key words: drug screening, ERK, breast cancer, apoptosis, Bcl-2 family proteins, drug repositioning, HIV-1 protease inhibitor, amprenavir induces apoptosis and inhibits tumor growth in human MCF-7 cancer cells both in vitro and in vivo, making amprenavir a promising candidate for future anticancer therapeutics.

\section{Introduction}

Despite substantial advances in cancer therapeutics, breast cancer remains a fundamental public health burden worldwide $(1,2)$. One of the most appealing chemotherapies against breast cancer is inducing the expression of Bim, a pro-apoptotic Bcl-2 homology (BH)-3-only protein within Bcl-2 family (3), to mediate apoptotic cancer cell death. However, Bim-targeted therapies may lead to acquired chemoresistance and tumor selectivity $(2,4)$ and thus limiting their clinical application. In addition to upregulated levels of $\mathrm{Bim}_{\mathrm{EL}}$ (an isoform of Bim protein), multiple breast cancer cells have recently been established to express elevated phosphorylated forms of Bim $\mathrm{EL}_{\mathrm{L}}$ (such as phospho-Ser69), which jointly determine the fate of breast cancer cells (5). Although $\mathrm{Bim}_{\mathrm{EL}}$ is well-known for its apoptosisinducing activity, the fact that constitutively overexpressed Bim $_{\mathrm{EL}}$ do not kill cancer cells suggests a potential pro-survival function of phosphorylated $\mathrm{Bim}_{\mathrm{EL}}$. Studies demonstrate that extracellular signal-regulated kinase 1/2 (ERK1/2)-mediated phosphorylation of $\mathrm{Bim}_{\mathrm{EL}}$ at Ser69 could enhance the proteosomal degradation of $\mathrm{Bim}_{\mathrm{EL}}(6)$ or reduce its sequestration with pro-survival molecules, such as Mcl-1, Bcl-xL and Bcl-2 (7), and thus it promotes cancer cell survival. Therefore, identification of compounds that can inhibit ERK1/2 kinase activity is of considerably therapeutic interest for breast cancer.

In silico drug repositioning by screening existing approved drugs for previously unknown indications is therapeutically essential and efficient for drug discovery (8-10). The main method for computational drug repositioning is molecular docking screening, which aimed at predicting and stimulating the direct physical interactions between existing drugs and novel therapeutic targets $(11,12)$. As only one X-ray structure of ERK1 has been reported (13) while several high-resolution crystal structures of ERK2 in complex with selective inhibitors 
are available now, the search of FDA-approved drugs against ERK2 to screen novel ERK2 inhibitors become feasible.

In the present study, firstly we screened 1447 FDA-approved small molecule drugs and identified amprenavir as a potential ATP-competitive inhibitor of ERK2. Subsequently, we found amprenavir could inhibit the kinase activity of ERK2 and induce apoptosis in MCF-7 human breast cancer cells by inhibiting ERK2-mediated phosphorylation of $\mathrm{Bim}_{\mathrm{EL}}$ at Ser69. Furthermore, we confirmed the anti-proliferative and apoptosis-inducing activities of amprenavir in vivo. Taken together, these findings reveal the possible new therapeutic use of amprenavir and provide a paradigm of drug repositioning to maximize the additional therapeutic advantages of existing approved drugs.

\section{Materials and methods}

Molecular docking screening. The initial 3D structure of ERK2 (PDB ID: 2OJJ) (14) was downloaded from RCSB Protein Data Bank (PDB) (http://www.pdb.org/pdb/). After removing ligand and solvent molecules, hydrogens and standard charges were assigned to each atom with UCSF Chimera (15), and the inhibitor-binding cluster was generated using program sphere_selector (16). The screening library containing 1447 FDA-approved small molecule drugs was constructed from DrugBank (version 3.0, http://www.drugbank.ca/). After removing established drugs targeting ERK2, the remaining drugs were subjected to OpenBabel toolbox (http://openbabel.org/) (17) to convert the 3D MOL2 format, which were then uploaded to the ZINC database (http://zinc.docking. org/) (18) for structure editing. Docking screen was conducted by UCSF DOCK6.3 program (19) with amber force field. Firstly, flexible-ligand docking with grid scoring was performed, then, topmost poses of the pre-generated top 100 low-scored drugs were subjected to amber scoring for further refinement.

Molecular dynamics (MD) simulations. MD simulations were performed by GROMACS package (version 4.5) (20). Topmost structures of ERK2-amprenavir complex from previous docking screening were used as the initial conformations. Protein topology was constructed by GROMACS accessory pdb2gmx and ligand topology was processed by PRODRG2 server (21) with GROMOS96 43a1 forcefield (22). After two phases of equilibrations, a $5000 \mathrm{ps}$ MD simulation with the time step of $2 \mathrm{fs}$ was performed. The resulting trajectory files were viewed and analyzed using VMD software $(22,23)$ and UCSF Chimera (15).

Chemicals. Amprenavir purchased from Santa Cruz Biotechnology, Inc. (Santa Cruz, CA, USA) was dissolved in dimethyl sulfoxide (DMSO) to a stock concentration of $1 \mathrm{mM}$ and stored at $-20^{\circ} \mathrm{C}$. All other chemical reagents with the highest purity available were purchased from Sigma-Aldrich.

Cell culture and cytotoxicity assay. Human breast cancer MCF-7 cells were incubated in Dulbecco's modified Eagle's medium (DMEM) supplemented with $10 \%$ fetal bovine serum (FBS) (both from Gibco, Grand Island, NY, USA), $100 \mathrm{U} / \mathrm{ml}$ penicillin and $100 \mathrm{mg} / \mathrm{ml}$ streptomycin (both from Invitrogen, Carlsbad, CA, USA), and were maintained at $37^{\circ} \mathrm{C}$ and $5 \% \mathrm{CO}_{2}$ in a humidified atmosphere.
Prior to drug treatment, MCF-7 cells were seeded in a 96-well plate for $24 \mathrm{~h}$. Serial doses of amprenavir were then added and cells were allowed to grow for additional 24 or $48 \mathrm{~h}$. Cytotoxic effects were measured by MTT assay with a spectrophotometer (Model 3550 Microplate Reader; Bio-Rad, Hercules, CA, USA) and the cell growth inhibition rate was calculated as follows:

Cell growth inhibitory rate $(\%)=\frac{A_{540}(D M S O)-A_{540}(\text { Amprenavir })}{A_{540}(D M S O)-A_{540}(\text { Blank })} \times 100 \%$

Cell morphology observation and staining. MCF-7 cells were treated with various concentrations of amprenavir $(0,50,100$, 150 and $200 \mu \mathrm{M})$ and then observed by a phase-contrast microscope (Leica, Wetzlar, Germany). In addition, Hoechst 33258 staining was applied and cells were analyzed by a fluorescence microscope (Leica).

Cell cycle and apoptosis analysis. MCF-7 cells treated with amprenavir or PBS for $24 \mathrm{~h}$ and $48 \mathrm{~h}$ were harvested, and cells at different phases of cell cycle were measured by FACScan flow cytometer (Becton-Dickinson, Franklin Lakes, NJ, USA). Annexin V (AV)/propidium iodide (PI) staining assays were performed using AV-fluorescein isothiocyanate (FITC) apoptosis detection kit (BD Pharmingen, San Diego, CA, USA), and different phases of apoptotic cells were measured by FACScan flow cytometer.

Western blot analysis. MCF-7 cells were treated with DMSO or amprenavir for indicated time periods. Then, both adherent and floating cells were collected and western blot analysis was conducted as previously described (24). Primary antibodies and horseradish peroxidase-conjugated secondary antibody were purchased from Zymed (San Francisco, CA, USA).

Expression and purification of recombinant proteins. Plasmids for ERK2/pT/pY, ERK2/T183A/pY and ERK2/ $\mathrm{pT} / \mathrm{Y} 185 \mathrm{~F}$ containing His6-tag were kindly provided by Dr Yi Wang (Nationwide Children's Hospital, USA). Plasmids were transformed into $E$. coli BL21 cells and protein expression was achieved by inducing cells with $0.4 \mathrm{mM}$ isopropyl-b-D-thiogalactopyranoside (IPTG) at $22^{\circ} \mathrm{C}$ for $4 \mathrm{~h}$. Then proteins were isolated by Ni-nitrilotriacetic acid (NTA)agarose chromatography (GE Healthcare Bio-Sciences, Pittsburgh, PA, USA) and quantified by NanoDrop spectrophotometer (Life Science).

Small interfering RNA (siRNA) transfection. MCF-7 cells were transfected with siRNAs against intracellular ERK2 and Bim $_{\mathrm{EL}}$ using Lipofectamine 2000 (Invitrogen) according to the manufacturer's instructions. Transfection efficiency was identified by western blotting and cells were used for further experiments $24 \mathrm{~h}$ later.

DNA constructs and mutagenesis. PCR-amplified hemagglutinin (HA)-tagged ERK2 and Flag-tagged Bim EL $_{\text {were }}$

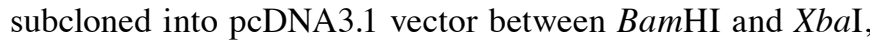
respectively. pcDNA 3.1-ERK2/T183A/pY, ERK2/pT/Y185F and pcDNA 3.1-Bim ${ }_{\mathrm{EL}}$ (S69A), Bim ${ }_{\mathrm{EL}}$ (S69E) were made using the QuikChange site-directed mutagenesis kit (Stratagene). 
Transient expression, stable transfection and immunoprecipitation. Transient expression and immunoprecipitation were conducted as previously described (25). Briefly, MCF-7 cells were plated at a density of $4 \times 10^{5} /$ well of a 6 -well plate $16 \mathrm{~h}$ prior to transfection. Cells were transiently transfected with the indicated plasmids using Expressfect Transfection reagents (Denville Scientific). Forty-eight hours after transfection, cell cultures were cultivated for another 2 weeks in the presence of active G418 (400 $\mu \mathrm{g} / \mathrm{ml})$ (Gibco). Antibiotic-resistant colonies that stably expressed indicated proteins were picked, pooled, identified and expanded for further experiments. After 24-48 $\mathrm{h}$ transfection with the indicated recombinants, MCF-7 cells were exposed to various doses of amprenavir for another $24 \mathrm{~h}$. Then the indicated proteins were pulled down with the Pierce HA (or Flag) Tag IP/Co-IP kit (Thermo Scientific) according to the manufacturer's instructions.

In vitro kinase assays. Bacterially purified or immunoprecipitated wild-type and mutant ERK2s were incubated for $20 \mathrm{~min}$ at $30^{\circ} \mathrm{C}$ in kinase buffer (10 mM Tris- $\mathrm{HCl}(\mathrm{pH} 7.4), 5 \mathrm{mM} \mathrm{MnCl}{ }_{2}$ and $1 \mathrm{mM}$ dithiothreitol) containing $20 \mu \mathrm{M}$ ATP and $10 \mu \mathrm{Ci}$ $\left[\gamma-{ }^{32} \mathrm{P}\right]$ ATP (Perkin-Elmer) with myelin basic protein (MBP) or $\mathrm{Bim}_{\mathrm{EL}}$ as a substrate. The final concentrations of amprenavir were 0-200 $\mu \mathrm{M}$. Reactions were stopped with an equal volume of $2 \mathrm{X}$ SDS-PAGE loading buffer and then heated to $100^{\circ} \mathrm{C}$. Proteins were isolated by SDS-PAGE and transferred onto polyvinylidene difluoride (PVDF) membranes. Then ${ }^{32} \mathrm{P}$ incorporation into substrate was detected by exposing the membrane to X-ray film.

In vivo kinase assays. After knockdown of intracellular ERK2 and Bim $_{\mathrm{EL}}$, wild-type and mutant ERK2 and Bim $\mathrm{EL}_{\mathrm{L}}$ plasmids were transfected into MCF-7 cells. The stably transfected cells were metabolically labeled with ${ }^{32} \mathrm{P}$ for $4 \mathrm{~h}$ and then treated with amprenavir $(150 \mu \mathrm{M})$ or $0.01 \%$ DMSO for $24 \mathrm{~h}$. ERK2-Bim ${ }_{\mathrm{EL}}$ complex was isolated and ${ }^{32} \mathrm{P}$ incorporation into Bim $_{\mathrm{EL}}$ was then detected as described previously (26). Western blot analysis with specific anti-phospho antibodies was conducted to analyze the phosphorylation of $\mathrm{Bim}_{\mathrm{EL}}$ by ERK2.

Xenograft studies. Male C57BL/6J nude mice (4-6 weeks old, weighing 18-22 g) were subcutaneously injected with MCF-7 cells, when tumors became palpable, mice were randomly divided into the following three groups ( $8 \mathrm{mice} / \mathrm{group})$ : vehicle control (normal saline), amprenavir (45 mg/kg/day, qld) and cisplatin $(5 \mathrm{mg} / \mathrm{kg} /$ day, q7d). The dosage of amprenavir used here was determined by our preliminary studies (data not shown). Amprenavir and cisplatin were intraperitoneally administered into mice, and the drug treatments lasted for 2 weeks. Tumor volume was measured by caliper according to formula ( $0.5 \mathrm{x}$ long-axis x short-axis x short-axis). Mice were sacrificed by cervical dislocation every three days and tumors were weighed. All animals were handled according to guidelines of the Institutional Animal Care and Use Committee of the Sichuan University in China (IACUC no. 20100318).

Immunohistochemistry staining. After two weeks of treatment, mice were sacrificed by cervical dislocation, and whole tumor tissues were harvested. Tumor tissues were fixed in $10 \%$ neutral buffered formalin for $24 \mathrm{~h}$ at room temperature, dehydrated, embedded in paraffin and sectioned. Tumor tissue sections were then processed for immunohistochemical staining with anti-proliferating cell nuclear antigen (PCNA) antibody and anti-cleaved caspase-3 antibody (both from CapitalBio Corporation). Apoptosis in tumor tissues were detected by terminal deoxynucleotidyl transferase-mediated dUTP nick-end labeling (TUNEL) staining using the Roche Fluorescence DeadEnd kit following the manufacturer's instructions (27). Representative images of each section were captured using a fluorescence microscopy (Nikon Eclipse 80i, Nikon, Tokyo, Japan).

Statistical analysis. Data on mouse body weight changes and the therapeutic efficacy (cell viability, tumor volume and tumor weight) were expressed as mean \pm SD from at least three independent experiments. Statistical significance was determined by Student's t-test and two-way analysis of variance (ANOVA) with $\mathrm{P}<0.05$ were considered as statistically significant, and $\mathrm{P}<0.01$ highly significant.

\section{Results}

In silico identification of amprenavir as a novel ERK2 inhibitor. Grid scoring and amber scoring were applied to predict novel approved drugs targeting ERK2 among the 1447 FDA-approved small molecule drugs, and MD simulations were then launched to stimulate the interaction pattern between ERK2 and the predicted drug (Fig. 1). After two rounds of docking screening, amprenavir appears to be the topmost low-scored drug potential as a candidate ERK2 inhibitor with the grid score and amber score of -62.397369 and -46.427078 , respectively. According to the data available in DrugBank, amprenavir is an HIV-1 protease inhibitor approved for the treatment of HIV infection, and has not been documented yet to target ERK2.

Subsequently, MD simulations were conducted to evaluate the interaction stabilities and mechanisms between ERK2 and amprenavir, and the root mean square deviations (RMSDs) of ERK2 backbone and amprenavir over the 5000 ps simulation process shown in Fig. 2, respectively. The chemical structure of amprenavir is illustrated in Fig. 3A. Overall, amprenavir binds to the hinge point between two domains of ERK2, in the ATP-binding site (Fig. 3B). Choosing the trajectory when the RMSDs of ERK2-amprenavir complex kept stable for at least $1 \mathrm{~ns}$ as the representative snapshot, two hydrogen bonds were formed between amprenavir and ERK2 with Arg54 and Lys41 as donors (Fig. 3C). Moreover, amprenavir was stabilized in the ATP-binding site via hydrophobic interactions with the nonpolar residues of ERK2 (Ile18, Ala22, Val26, Ala39, Ile43, Ile71 and Leu143) (Fig. 3D). These findings reveal that hydrogen bonds and van der Waals contacts can synergistically contribute to the stabilization of amprenavir in the ATP-binding site of ERK2.

Amprenavir inhibits the kinase activity of ERK2. To determine the inhibitory effects of amprenavir on the kinase activity of ERK2, kinase assays with MBP as a substrate were performed (Fig. 4). In the kinase system with bacterially purified recombinant ERK2s, exposure to $150 \mu \mathrm{M}$ amprenavir for $24 \mathrm{~h}$ completely blocked the phosphorylation of MBP by 


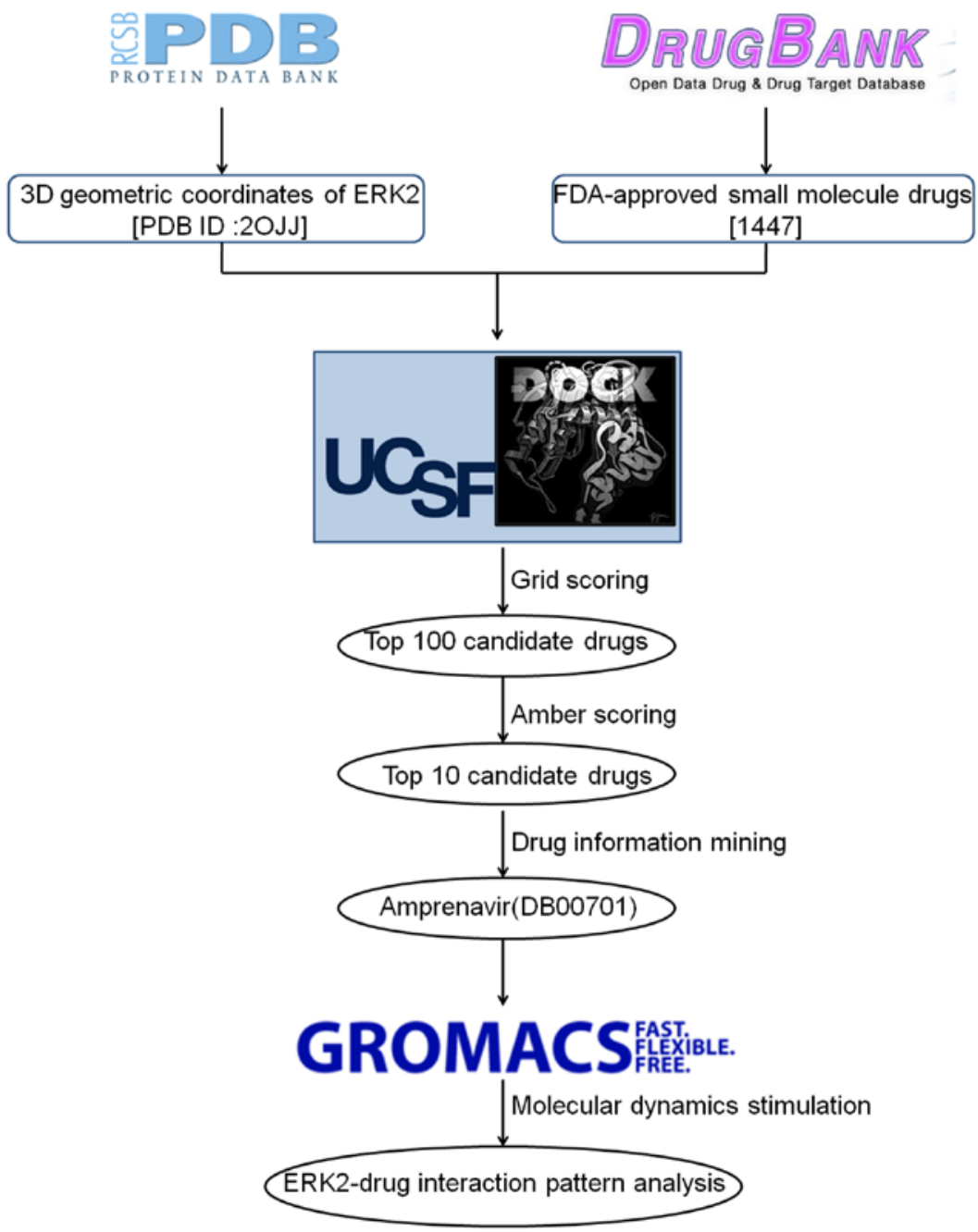

Figure 1. Schematic representation of the in silico screening work flow. 1447 FDA-approved small molecule drugs from DrugBank were virtually screened against the 3D structure of ERK2 to identify novel ERK2 inhibitors. After being scored by grid scoring and amber scoring in UCSF DOCK6, amprenavir appeared to be the most potent ERK2 inhibitor. MD simulations were then performed by GROMACS package to stimulate the interaction pattern between ERK2 and amprenavir.

A

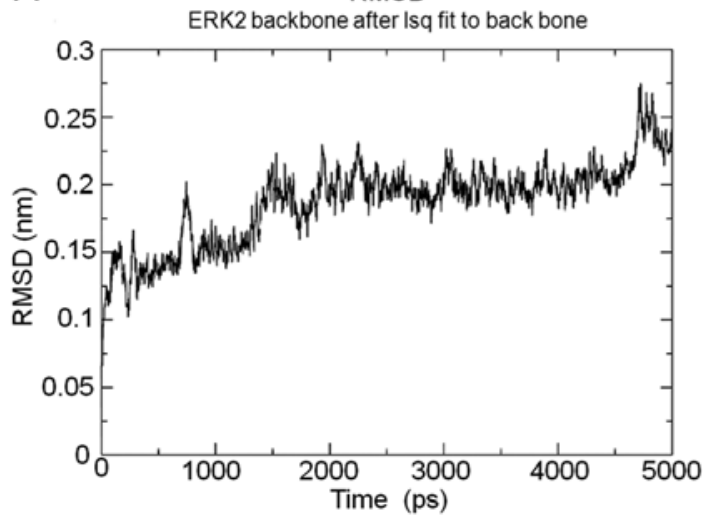

B

RMSD

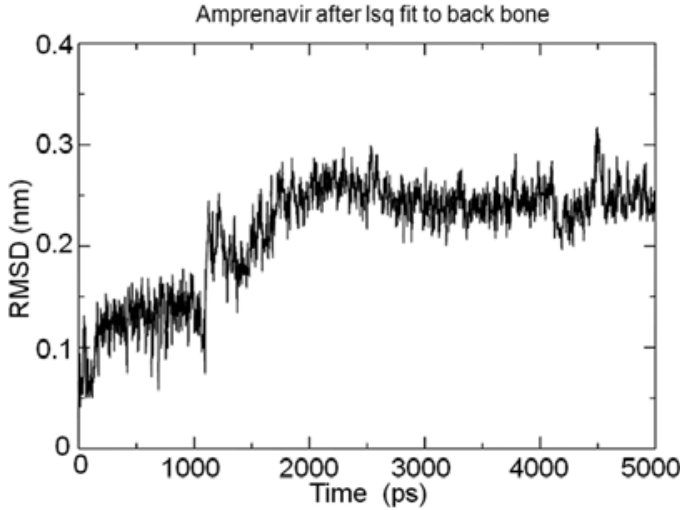

Figure 2. Time dependence of RMSD for ERK2 and amprenavir during 5000 ps MD simulations. (A) RMSD for the backbone of ERK2 and (B) RMSD for amprenavir during the 5,000 ps MD simulations.

ERK2/pTpY and ERK2/T183A/pY (Fig. 4A). Additionally, in the kinase system with ERK2s immunoprecipitated from transfected MCF-7 cells, MBP was significantly phosphorylated by dually phosphorylated ERK2/pTpY in diluted DMSO, whereas this phosphorylation phenomenon disappeared after $150 \mu \mathrm{M}$ amprenavir treatment (Fig. 4B), confirming that amprenavir could potently inhibit the kinase activity of ERK2. We then examined if amprenavir could exert an influence on ERK2 
A

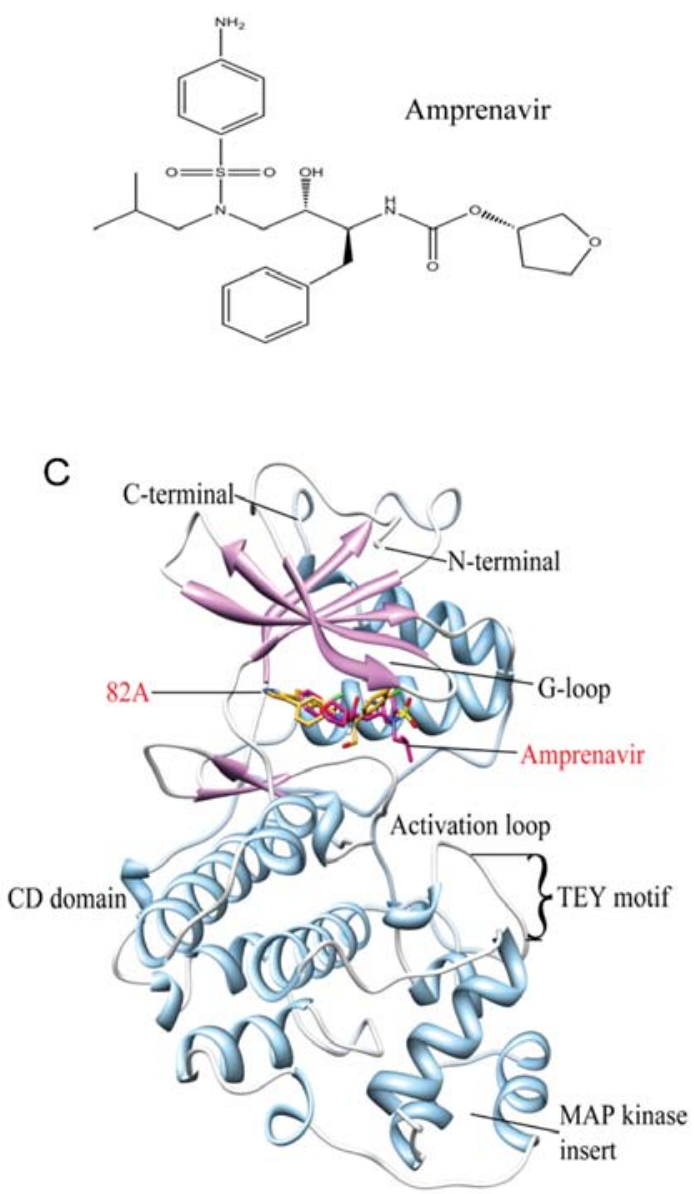

B

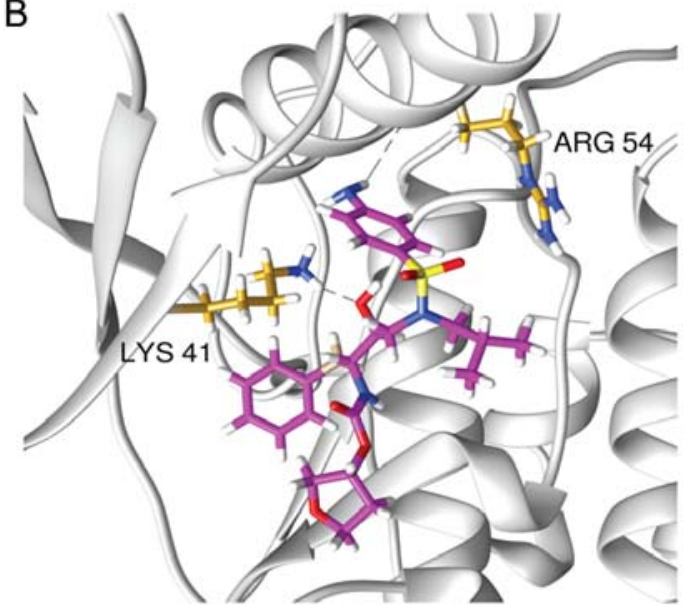

D

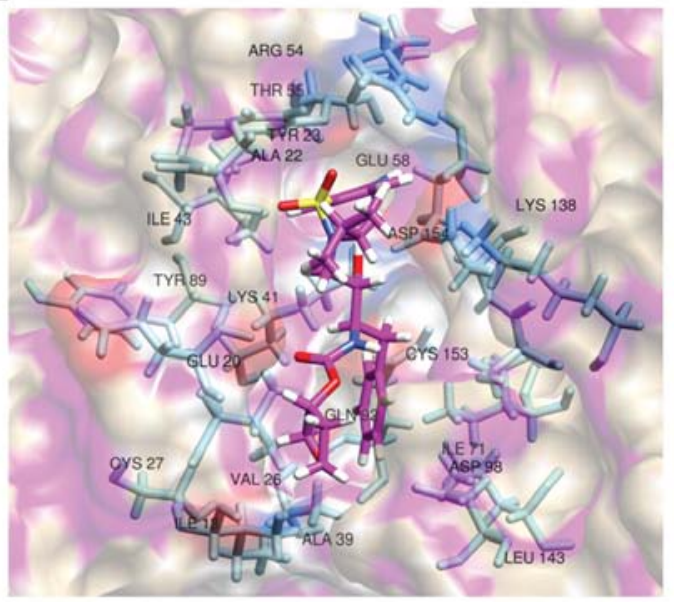

Figure 3. In silico identification of amprenavir as a novel ERK2 inhibitor. (A) The chemical structure of amprenavir presented by the ChemDraw Ultra 12.0 program. (B) Comparative view of the binding pattern of 82A (ligand of ERK2 with the PDB ID: 2OJJ) and amprenavir in the ATP-binding site of ERK2 displayed by UCSF Chimera. Carbon atoms of 82A and amprenavir are shown in gold and magenta, respectively, while the $\alpha$-helix and $\beta$-sheet of ERK 2 are indicated in sky blue and orchid, respectively. (C) Hydrogen bond interaction pattern between ERK2 and amprenavir from representative trajectory snapshot in MD simulations. Carbon atoms of amprenavir and the Lys41 and Arg54 of ERK2 are colored in magenta and goldenrod, respectively, and the hydrogen bonds are represented as dark dashed lines by UCSF Chimera. (D) Hydrophobic interactions between the nonpolar residues of ERK2 and amprenavir from representative trajectory snapshot in MD simulations. Carbon of atoms the nonpolar residues of ERK2 are colored in cyan and represented as hydrophobic surface, and the carbon atoms of amprenavir are colored in magenta by UCSF Chimera.

activation by detecting total ERK2 and fully activated ERK2 in MCF-7 cells. As shown in Fig. 4C and D, increasing doses of amprenavir did not affect the activation of ERK2, whereas exposure to $150 \mu \mathrm{M}$ amprenavir for 0 to $48 \mathrm{~h}$ inhibited the activation of ERK2 to some extent. These findings demonstrated that amprenavir may inhibit the catalytic activity of ERK2 while having little inhibitory effect on its activation.

Amprenavir inhibits proliferation and induces apoptosis in MCF-7 cells. Given the implications of ERK2 signaling pathways in tumor progression, we explored the antitumor effects of amprenavir in MCF-7 cells. According to results of MTT assays, amprenavir inhibited the proliferation of MCF-7 cells in a time-dependent and dose-dependent manner (Fig. 5A), and the $\mathrm{IC}_{50}$ values were $\sim 150$ and $105 \mu \mathrm{M}$ for 24 and $48 \mathrm{~h}$, respectively.

Then, cell and nuclear morphology were observed to determine if apoptosis was involved in this anti-proliferative activity. When observed by phase-contrast microscopy, MCF-7 cells treated with amprenavir for 24 or $48 \mathrm{~h}$ showed typical morphological characteristics of apoptosis (28), such as reduction in cell volume, rounding up of cells, cell shrinkage and membrane blebbing. Moreover, Hoechst 33258 staining of DMSO-treated MCF-7 cells exhibited normal nuclear morphology and homogeneously stained chromatin, whereas amprenavir-treated cells showed an apoptotic nuclear morphology (29) with shrunken, fragmented nuclei and brighter hypercondensed chromatin (Fig. 5B).

When MCF-7 cells were treated with $150 \mu \mathrm{M}$ for different time periods, expression levels of pro-caspase-3, -8 and -9 were decreased, whereas expression of caspase-3, -8 and -9 were increased along with treatment time (Fig. 5C), indicating that amprenavir could time-dependently activate caspase-3, -8 and -9 and thus induce apoptosis in MCF-7 cells.

Flow cytometry to analyze cell cycle arrest and detect different phases of apoptotic cells. Cell cycle analysis showed that amprenavir treatment significantly upregulated the proportions of MCF-7 cells in sub-G1 and G1 phase, suggesting that amprenavir may trigger sub-G1 and G1 phase arrest along with the culturing time (Fig. 6A). AV/PI staining 

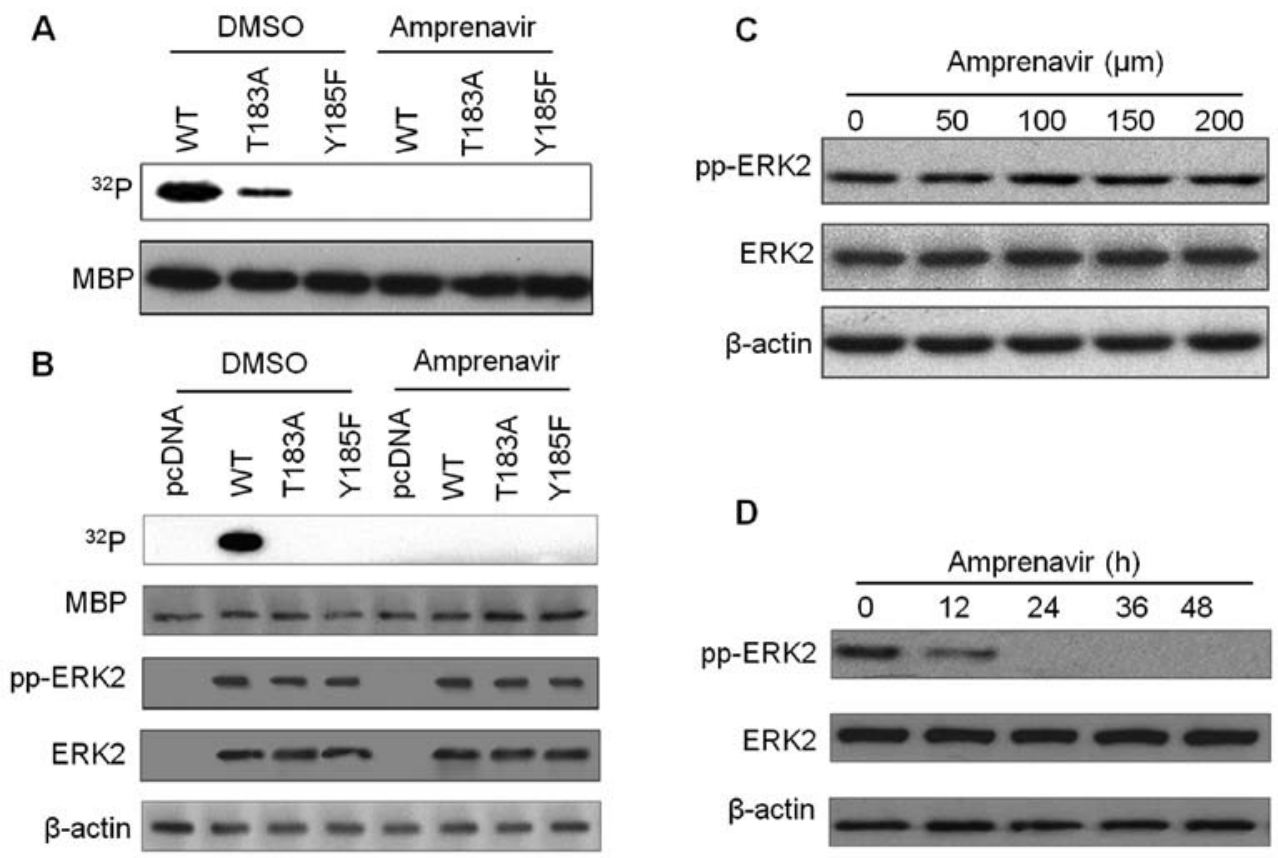

Figure 4. Amprenavir inhibits the kinase activity and activation of ERK2. (A) Bacterially purified recombinant dually phosphorylated ERK2/pTpY, mono-phosphorylated ERK2/T183A/pY or ERK2/pT/pY185A was added in the kinase system with MBP as a substrate, and then in vitro ERK2 kinase assay with or without amprenavir treatment $(150 \mu \mathrm{M}, 24 \mathrm{~h})$ were performed. ${ }^{32} \mathrm{P}$ incorporation into MBP was detected by X-ray film. (B) Wild-type or mutant ERK2s were immunoprecipitated from MCF-7 cells transfected with indicated ERK2 constructs, then in vitro kinase assays with immunoprecipitated ERK2s and MBP with or without amprenavir treatment were conducted $(150 \mu \mathrm{M}, 24 \mathrm{~h}) .{ }^{32} \mathrm{P}$ incorporation into MBP was detected by X-ray film. Western blotting using anti-ERK2 and anti-pp-ERK2 (T183/Y185) antibodies were performed to indicate the expression and activation levels of ERK2. $\beta$-actin was used as an equal loading control. (C) MCF-7 cells were exposed to a series of concentrations of amprenavir for $24 \mathrm{~h}$, and the dose responses of ERK2 and pp-ERK2 were examined via western blotting with anti-ERK2 and anti-pp-ERK2 (T183/Y185) antibodies. (D) MCF-7 cells were exposed to $150 \mu \mathrm{M}$ amprenavir for the indicated time periods, and the time responses of ERK2 and pp-ERK2 were evaluated via western blotting with anti-ERK2 and anti-pp-ERK2 (T183/Y185) antibodies.

results showed that amprenavir treatment reduced the number of live cells and increased the number of early and late apoptotic cells, and percentages of early apoptotic cells were significantly higher than late apoptotic cells (Fig. 6B), suggesting that amprenavir could effectively induce apoptosis in a time-dependent manner.

Amprenavir inhibits ERK2-mediated phosphorylation of Bim $_{E L}$ at Ser69. Phosphorylation of Bim $\mathrm{EL}_{\text {at }}$ at69 may greatly facilitate ERK2-induced apoptosis, therefore, we performed kinase assays to evaluate the inhibitory effects of amprenavir on ERK2-mediated phosphorylation of Bim $_{\mathrm{EL}}$ at $\mathrm{S69}$. As shown in Fig. 7A, with bacterially purified wild-type $\mathrm{Bim}_{\mathrm{EL}}$ or $\mathrm{Bim}_{\mathrm{EL}}$ mutant as a substrate, strong phosphorylation of $\mathrm{Bim}_{\mathrm{EL}}$ (WT) was observed in diluted DMSO, whereas replacement of Ser69 with glutamic acid (S69E) partially suppressed this phosphorylation phenomenon, revealing the involvement of S69 in ERK2-mediated Bim ${ }_{\mathrm{EL}}$ phosphorylation. After $150 \mu \mathrm{M}$ amprenavir treatment, we failed to detect any phosphorylation of $\mathrm{Bim}_{\mathrm{EL}}$ (WT), $\mathrm{Bim}_{\mathrm{EL}}$ (S69A) and $\mathrm{Bim}_{\mathrm{EL}}$ (S69E), demonstrating that amprenavir inhibited phosphorylation of $\mathrm{Bim}_{\mathrm{EL}}$ at S69. Similarly, using ${ }^{32} \mathrm{P}$-metabolically labeling MCF-7 cells cotransfected with active ERK2 and indicated $\mathrm{Bim}_{\mathrm{EL}}$ constructs, we found that $150 \mu \mathrm{M}$ amprenavir treatment could completely interrupt the phosphorylation phenomena in $\mathrm{Bim}_{\mathrm{EL}}$ (WT), $\mathrm{Bim}_{\mathrm{EL}}$ (S69A) and $\mathrm{Bim}_{\mathrm{EL}}$ (S69E) (Fig. 7B), indicating that amprenavir inhibited ERK2-mediated phosphorylation of $\mathrm{Bim}_{\mathrm{EL}}$ at $\mathrm{S} 69$ in MCF-7 cells. As an alternative, specific antibody against
phospho-S69-Bim ${ }_{\mathrm{EL}}$ was used. As shown in Fig. 7B, in DMSO group, phospho-S69-Bim ${ }_{\mathrm{EL}}$ could be detected in MCF-7 cells transfected with $\mathrm{Bim}_{\mathrm{EL}}$ (WT) and $\mathrm{Bim}_{\mathrm{EL}}$ (S69E), while the signals became significantly weaker after $150 \mu \mathrm{M}$ amprenavir treatment. Moreover, amprenavir dose- and time-dependently reduced the expression levels of phospho-S69-Bim $\mathrm{EL}_{\mathrm{EL}}$ with the total amounts of $\mathrm{Bim}_{\mathrm{EL}}$ keeping constant (Fig. 7C and D). Taken together, these results suggest that amprenavir could effectively inhibit ERK2-mediated phosphorylation of $\mathrm{Bim}_{\mathrm{EL}}$ at $\mathrm{S} 69$ without affecting the expression levels of total $\mathrm{Bim}_{\mathrm{EL}}$ in MCF-7 cells.

Antitumor effects and mechanisms of amprenavir in MCF-7 xenograft models. MCF-7 xenograft models were constructed to establish the antitumor effects and mechanisms of amprenavir in vivo with the administration of DMSO and cisplatin as blank and positive control, respectively. In general, administration of amprenavir significantly inhibited the growth of MCF-7 tumors from day 6 , and the growth inhibitory effects exhibited a time-dependent manner $(\mathrm{P}<0.001)$ (Fig. 8A-C). After 2 weeks of treatment, the average tumor volumes were inhibited by $78 \%$ (vehicle vs. amprenavir; mean, 0.50 vs. $0.11 \mathrm{~mm}^{3}$; difference, $0.39 \mathrm{~mm}^{3} ; \mathrm{P}=0.000007$ ) and tumor weights were inhibited by $77 \%$ (vehicle vs. amprenavir; mean, 1.16 vs. $0.27 \mathrm{~g}$; difference, $0.89 \mathrm{~g}$; $\mathrm{P}=0.000007$ ). Of note, treated mice with amprenavir for 9 days successfully suppressed tumor growth by $\sim 50 \%$. In addition, the therapeutic efficiency of amprenavir and cisplatin did not significantly differ from each other during the early time 

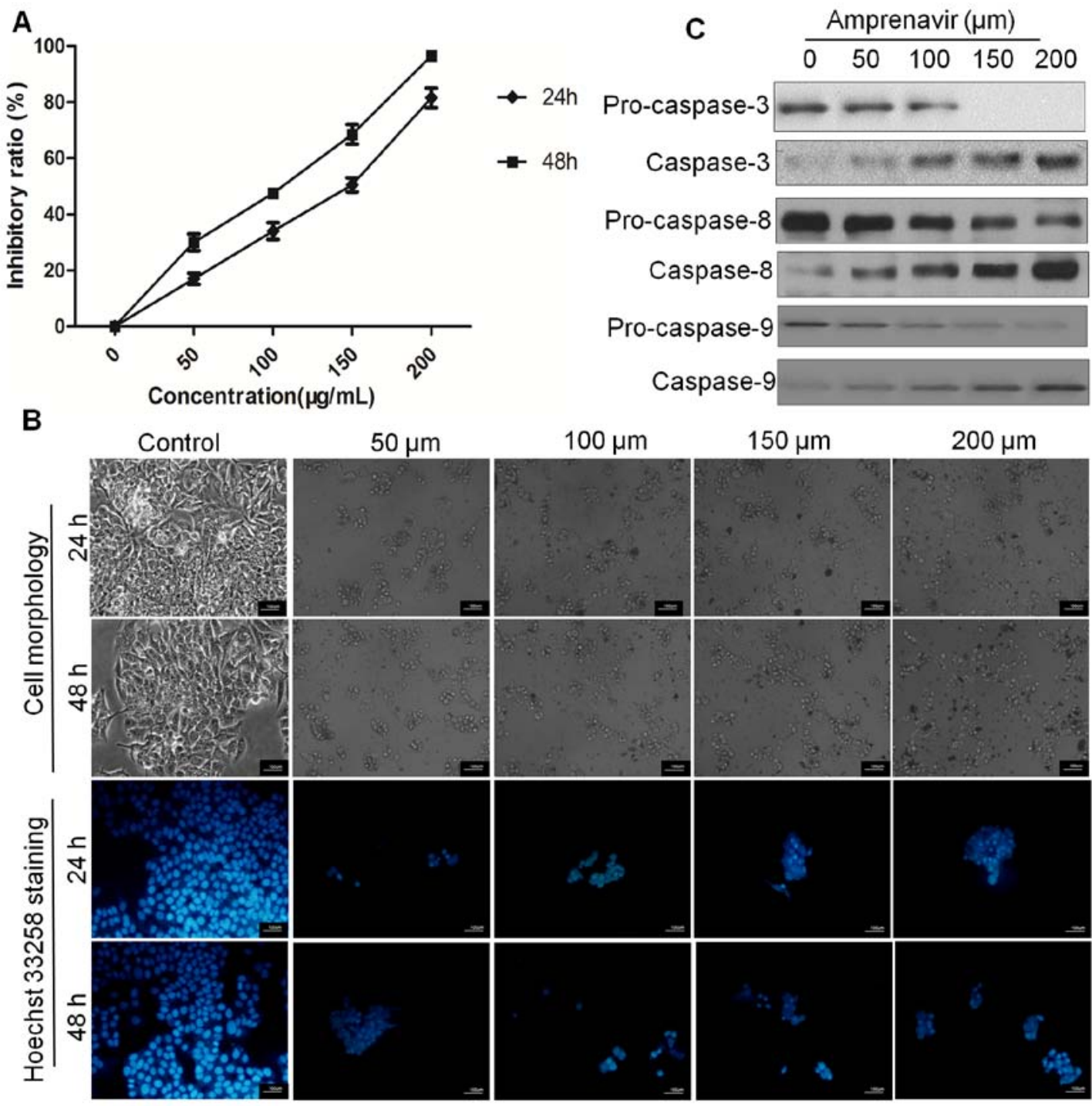

Figure 5. Amprenavir inhibits proliferation and induces apoptosis in MCF-7 cells. (A) Inhibitory ratio of MCF-7 cells after treatment with a series of concentrations of amprenavir determined by MTT assay (mean $\pm \mathrm{SD}, \mathrm{n}=3$ ) ( ${ }^{*} \mathrm{P}<0.05$ and ${ }^{* *} \mathrm{P}<0.01$ compared with control). (B) Apoptotic morphology of MCF-7 cells treated with various concentrations of amprenavir was observed using phase-contrast microscopy. Additionally, apoptotic nuclear morphology of MCF-7 cells was analyzed by Hoechst 33258 staining and observed using fluorescence microscopy. (C) MCF-7 cells were treated with various concentrations of amprenavir for $24 \mathrm{~h}$, and then expression levels of pro-caspase-3, caspase-3, pro-caspase-8, caspase-8, pro-caspase-9 and caspase- 9 were detected by western blotting using indicated antibodies.

periods of treatment. Regarding body weight change as an indication of general toxicity (Fig. 8D), average body weights of amprenavir and cisplatin-treated mice did not display a significant difference during the early periods of treatment, and amprenavir showed more moderate toxicity than cisplatin after day 9. Collectively, daily injecting mice with $45 \mathrm{mg} /$ $\mathrm{kg}$ /day amprenavir could effectively inhibit the growth of MCF-7 tumor xenografts, and for early periods of treatment, its therapeutic efficiency was comparable to cisplatin, which is a clinically widely used antitumor agent.

Immunohistochemical staining was then conducted to validate the antitumor mechanisms of amprenavir in vivo. Proliferation of MCF-7 xenografts in different treatment groups was evaluated by the localization of PCNA (Fig. 9A), and 2 weeks of amprenavir treatment showed significant anti-proliferative effects, which was even comparable to that of cisplatin (Fig. 9B). Moreover, cleaved caspase-3 staining and TUNEL staining results indicated that apoptosis was widely distributed in tumor specimens exposed to amprenavir treatment for 2 weeks (Fig. 9C and E). Statistical analysis confirmed a significant apoptosis level in amprenavir-treated MCF-7 xenografts, which was only slightly weaker than cisplatin-treated groups (Fig. 9D and F) $(\mathrm{P}<0.01)$.

\section{Discussion}

In the present study, for the purpose of repositioning existing approved drugs for novel anticancer uses, we launched a structure-based virtual screening of 1447 FDA-approved small molecule drugs against ERK2. As a result, we identified amprenavir, a HIV-1 protease inhibitor, as a potent kinase inhibitor of ERK2, and this activity was further confirmed to contribute to its anti-proliferative and apoptosis-inducing effects in MCF-7 breast cancer cells both in vitro and in vivo.

According to our in silico screening results, among the top 10 drugs predicted to target ERK2, three drugs (amprenavir, 

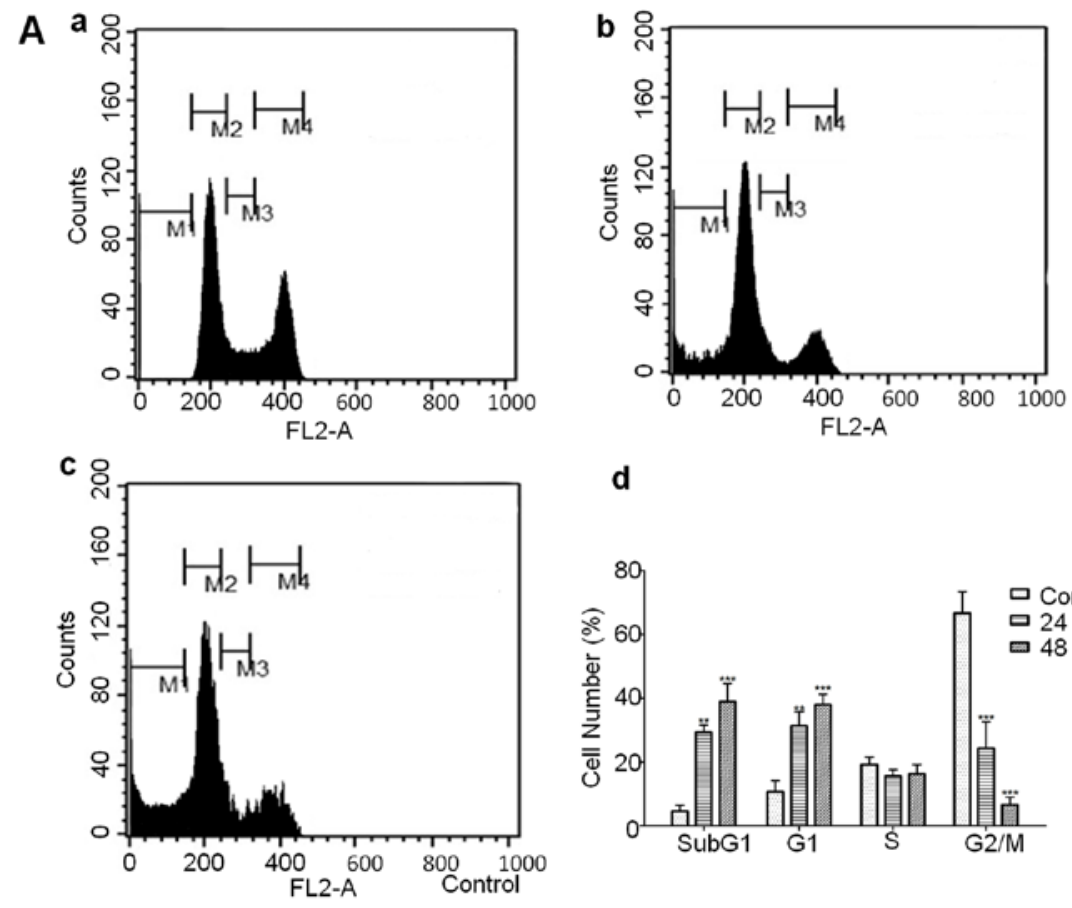

d
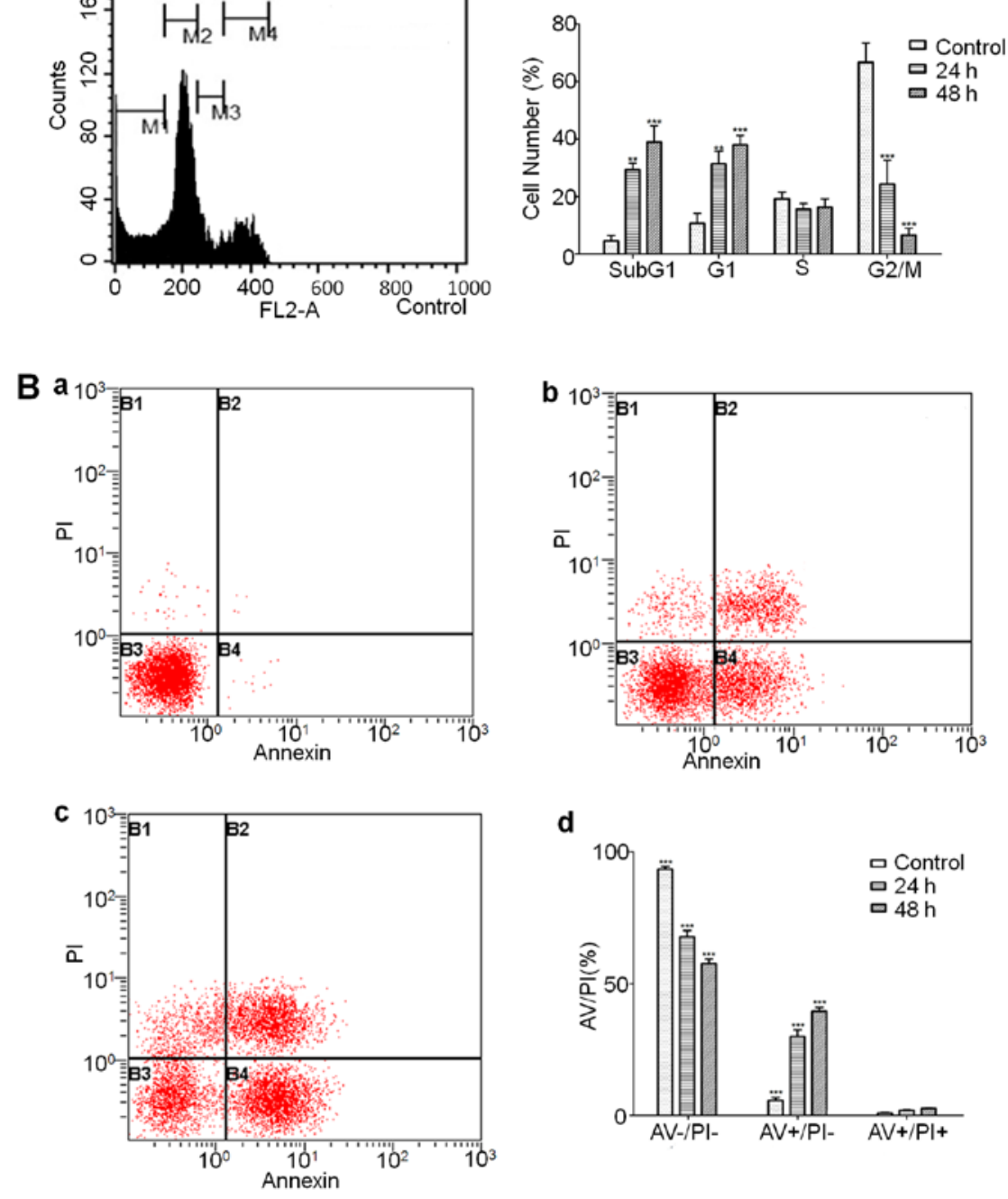

Figure 6. Amprenavir inhibits cell cycle progression and induces apoptosis in MCF-7 cells. (A) Cell cycle analysis of MCF-7 cells untreated or treated with $150 \mu \mathrm{M}$ amprenavir for 24 and $48 \mathrm{~h}$ using flow cytometry. (B) MCF-7 cells were exposed to $150 \mu \mathrm{M}$ amprenavir for 24 and $48 \mathrm{~h}$, and then percentages of different phase of apoptotic cells were analyzed by the $\mathrm{AV} / \mathrm{PI}$ double staining. $\mathrm{AV}-/ \mathrm{PI}^{-}, \mathrm{AV}^{+} / \mathrm{PI}^{-}$and $\mathrm{AV}^{+} / \mathrm{PI}^{+}$indicated live cells, early apoptotic cells and late apoptotic cells, respectively. All statistical data are represented by a bar diagram (mean $\pm \mathrm{SD}, \mathrm{n}=3 ;{ }^{*} \mathrm{P}<0.05$ and ${ }^{* *} \mathrm{P}<0.01$ compared with control).

indinavir and saquinavir) are established HIV-1 protease inhibitors approved for the treatment of HIV infection (data not shown). From the perspective of function, ERK2 has been reported to play important roles in the pathogenesis of HIV infection. For example, HIV-1 accessory protein Nef can act by activating the Ras-Raf-MAPK1/2 pathways (24), stimulating the transcription factor activating protein-1 through Hck and MAPK to increase CD4 T cell ERK activity (30), and thus affecting T cell activity, viral replication and viral infectivity (31). Therefore, ERK2 may be a latent target of HIV-1 proteases and its inhibition may facilitate the treatment of HIV infection. From the perspective of structure, although the backbone chains of HIV-1 protease and ERK2 hardly have any superposition, their ligand-binding cavities overlap by a large margin (data not shown), which may provide structural basis for the sharing of identical small molecule inhibitors between these two proteins.

Among varieties of in silico drug repositioning strategies, the combination of molecular docking and MD simulations, in 
A

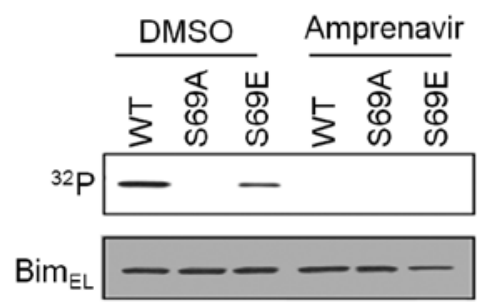

B

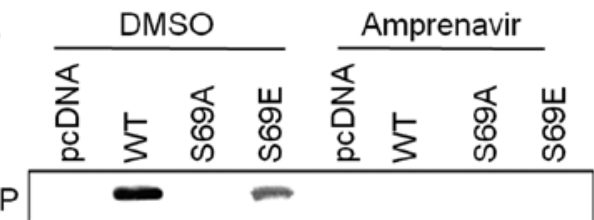

p-Bimet

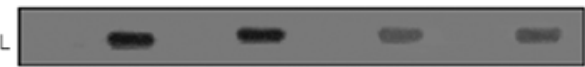

$\operatorname{Bim}_{E L}$

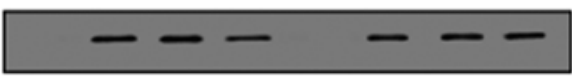

$\beta$-actin
C
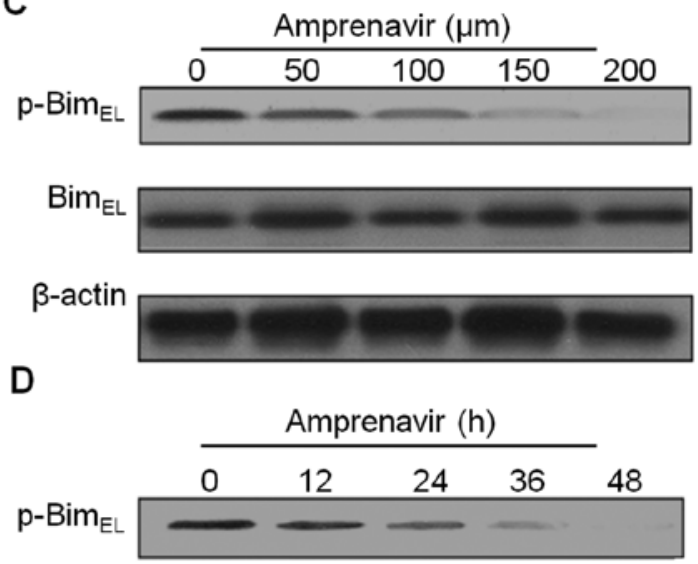

Bim $_{E}$

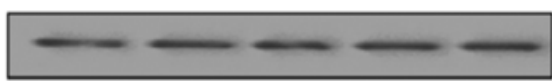

$\beta$-actin

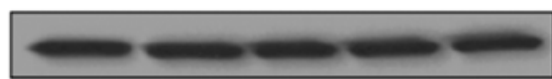

Figure 7. Amprenavir inhibits ERK2-mediated phosphorylation of $\mathrm{Bim}_{\mathrm{EL}}$ at S69. (A) In vitro kinase assays with active ERK2 and bacterially purified recombinant $\operatorname{Bim}_{\mathrm{EL}}(\mathrm{WT}), \operatorname{Bim}_{\mathrm{EL}}(\mathrm{S} 69 \mathrm{~A})$ or $\operatorname{Bim}_{\mathrm{EL}}(\mathrm{S} 69 \mathrm{E})$ as a substrate were performed. The kinase systems were exposed either to amprenavir $(150 \mu \mathrm{M}, 24 \mathrm{~h})$ or equal amount of DMSO. ${ }^{32} \mathrm{P}$ incorporation into MBP was detected by X-ray film. (B) ${ }^{32} \mathrm{P}$-metabolically labeling MCF-7 cells were cotransfected with active ERK2 and indicated $\mathrm{Bim}_{\mathrm{EL}}$ constructs $\left[\mathrm{Bim}_{\mathrm{EL}}\right.$ (WT), $\operatorname{Bim}_{\mathrm{EL}}(\mathrm{S} 69 \mathrm{~A})$ or Bim $\left.\mathrm{BL}_{\mathrm{EL}}(\mathrm{S} 69 \mathrm{E})\right]$, and then cells were treated with $150 \mu \mathrm{M}$ amprenavir or DMSO for $24 \mathrm{~h} .{ }^{32} \mathrm{P}$ incorporations into Bim $\mathrm{EL}_{\mathrm{L}}$ were detected by X-ray film, western blotting using anti-Bim $\mathrm{EL}_{\mathrm{LL}}$ and anti-phospho-S69-Bim $\mathrm{EL}_{\mathrm{E}}$ antibodies were performed to indicate the expression and phosphorylation levels of $\mathrm{Bim}_{\mathrm{EL}}$. $\beta$-actin was used as an equal loading control. (C) MCF-7 cells were exposed to a series of concentrations of amprenavir for $24 \mathrm{~h}$, and the dose responses of $\mathrm{Bim}_{\mathrm{EL}}$ and p-Bim $\mathrm{EL}_{\mathrm{L}}(\mathrm{S} 69)$ were examined by western blotting using anti-Bim $\mathrm{EL}_{\mathrm{EL}}$ and antiphospho-S69-Bim $\mathrm{EL}_{\mathrm{L}}$ antibodies. (D) MCF-7 cells were exposed to $150 \mu \mathrm{M}$ amprenavir for the indicated time periods, and the time responses of Bim $\mathrm{EL}_{\mathrm{EL}}$ and $\mathrm{p}-\mathrm{Bim}_{\mathrm{EL}}(\mathrm{S} 69)$ were determined by western blotting using anti-Bim $\mathrm{EL}_{\mathrm{EL}}$ and anti-phospho-S69-Bim $\mathrm{EL}_{\mathrm{EL}}$ antibodies.

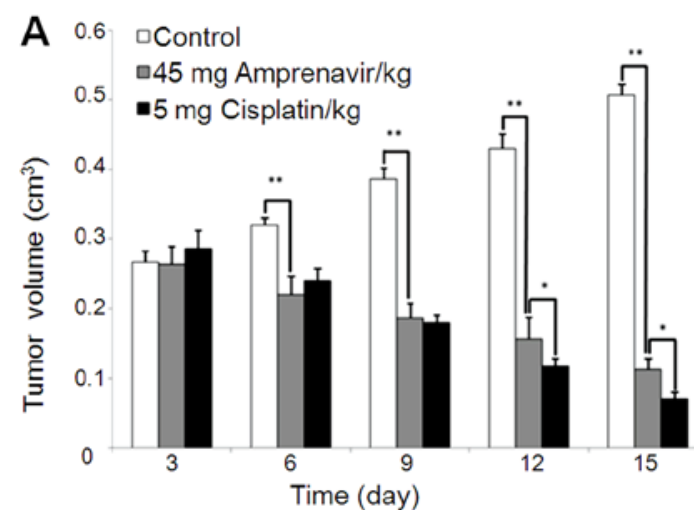

C

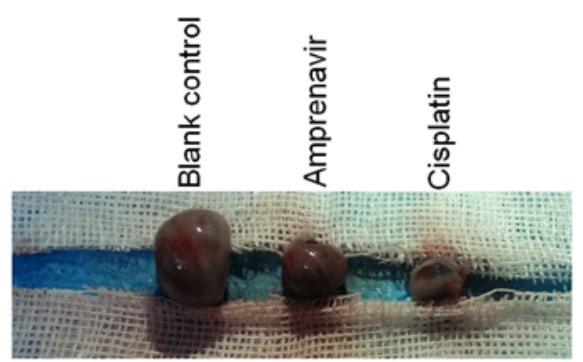

B

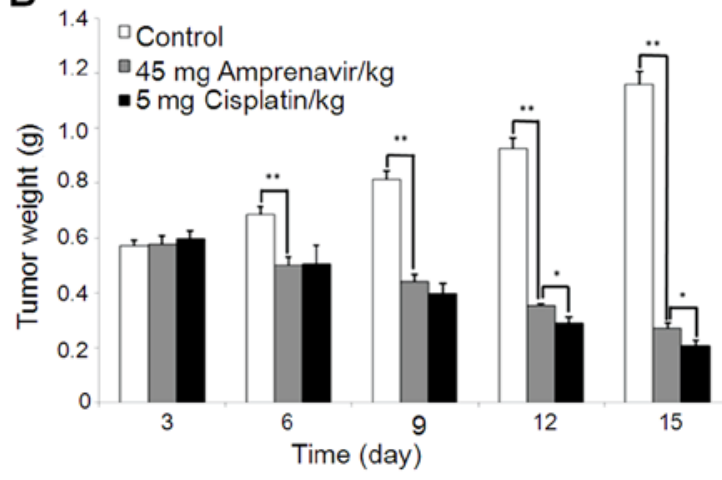

D ${ }_{27.3}$

$$
\begin{array}{ll}
26.8 & \square 45 \mathrm{mg} \mathrm{Amprenavir} / \mathrm{kg} \\
& \square 5 \mathrm{mg} \mathrm{Cisplatin} / \mathrm{kg}
\end{array}
$$
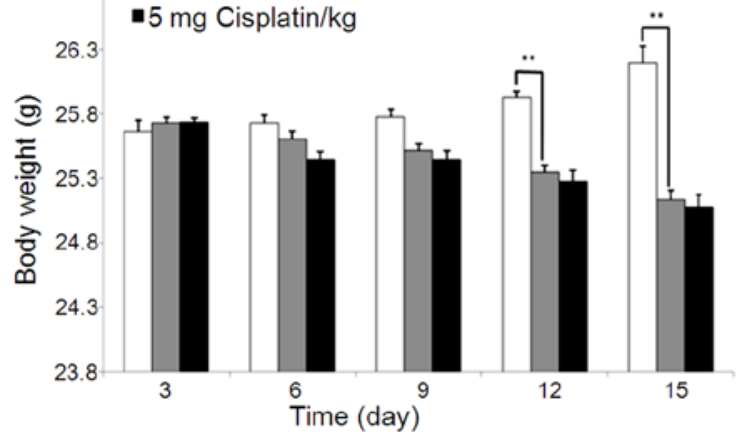

Figure 8. Antitumor effects of amprenavir in MCF-7 xenograft models. MCF-7 tumor-bearing mice were administrated with PBS, amprenavir (45 mg/kg, q1d) and cisplatin $(5 \mathrm{mg} / \mathrm{kg}$ ) for 2 weeks. (A) Tumor volume variance of MCF-7-bearing mice under different treatment by caliper according to formula (0.5 x longaxis x short-axis x short-axis). (B) Tumor weight variety of MCF-7-bearing mice under different treatment. (C) Comparison of antitumor effects of amprenavir and cisplatin at day 10. (D) Body weight change of MCF-7-bearing mice under different treatment. All statistical data are represented by a bar diagram (mean $\pm \mathrm{SD}, \mathrm{n}=3 ;{ }^{*} \mathrm{P}<0.05$ and ${ }^{* *} \mathrm{P}<0.01$ compared with control). 

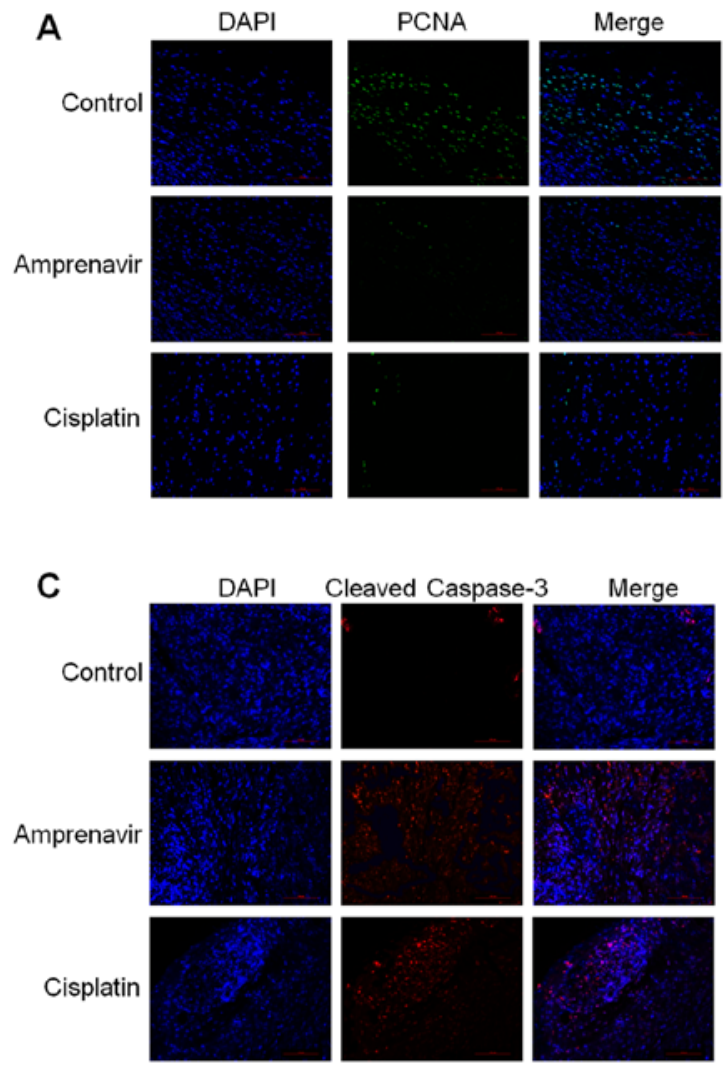

E
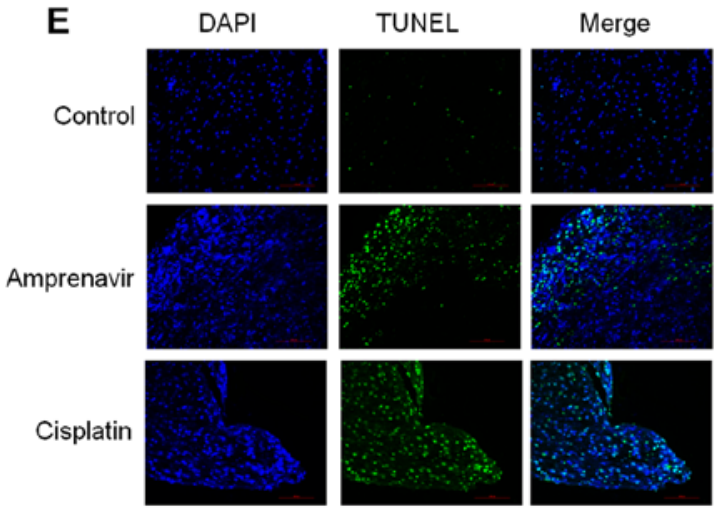

B

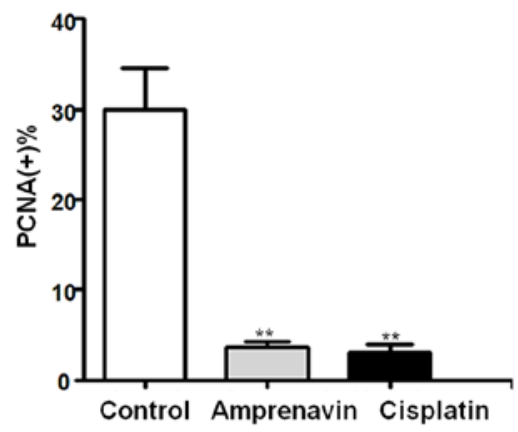

D

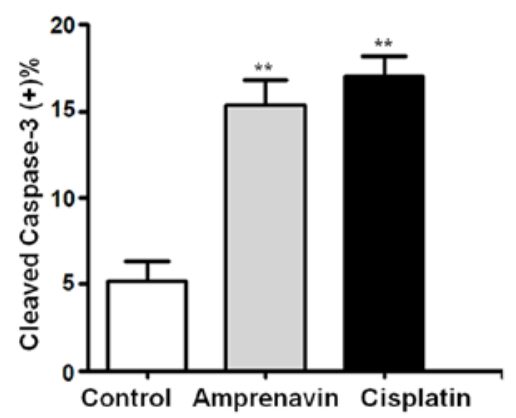

$\mathbf{F}$

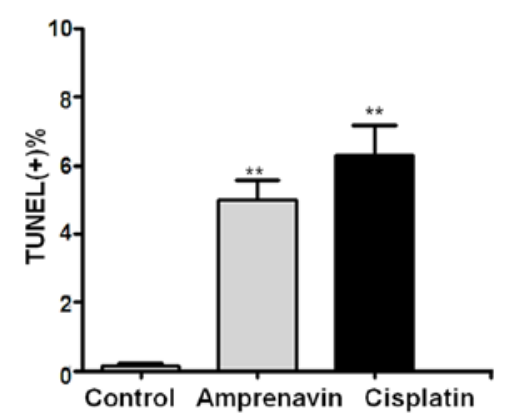

Figure 9. In vivo effects of amprenavir on the proliferation and apoptosis of MCF-7 xenograft models identified by immunohistochemical staining. Representative immunohistochemical images of PCNA staining (A), cleaved caspase-3 staining (C) and TUNEL staining (E) after two weeks of treatment, and comparison of PCNA-positive rates (B), cleaved caspase-3-positive rates (D) and TUNEL-positive rates (F) amongst different treatment groups on day 15 indicated the anti-proliferation and apoptosis-inducing effects of amprenavir in vivo. Proliferation in tumor tissues was determined by immunohistochemical staining using anti-PCNA and anti-cleaved caspase-3 antibodies, apoptosis in tumor tissues was detected by TUNEL staining using the Roche fluorescence DeadEnd kit. All statistical data are represented by a bar diagram (mean $\pm \mathrm{SD}, \mathrm{n}=3 ;{ }^{*} \mathrm{P}<0.05$ and ${ }^{* *} \mathrm{P}<0.01$ compared with control).

which docking is first utilized to fast screen of large libraries and MD simulations are then applied to optimize the conformations of protein-drug complexes, is probably a rational protocol to accelerate the virtual screening process (12). According to the binding mechanisms analyzed by MD simulations (Fig. 3C and D), some interactions between amprenavir and ERK2 are conserved compared with other reported ERK2inhibitor complexes. For example, the hydrophobic interactions between amprenavir and the non-polar groups Leu143 and Cys153 are consistent with the published X-ray crystallographic data (32) and structure-based virtual screening studies $(33,34)$, suggesting the importance of these two residues in accommodating an inhibitor in the ATP-binding site of ERK2. Moreover, interactions between the terminal groups of amprenavir with Lys41 and Asp154 in ERK2 have been established to make ample space available to fit the ligand substituent (32-34), and Gln92 has been demonstrated to provide structural basis for the inhibitor selectivity of ERK2 $(35,36)$. Collectively, these conserved residues can form hydrogen bonds or van der Waals interactions between amprenavir and ERK2, and further contribute to the selectivity and stabilization of amprenavir in the ATP-binding site of ERK2. Structural studies are needed to validate the detailed structure-activity relationships between amprenavir and ERK2, and improved therapeutic potency may be achieved by modifying the drug's chemical features or examining structurally similar compounds. 
HIV-1 proteinase inhibitors, such as ritonavir, saquinavir, atazanavir and nelfinavir, have demonstrated broad-spectrum antitumor activities and diverse action mechanisms (37-40). However, the antitumor potentials of amprenavir have not yet been well-clarified. Amprenavir (agenerase, GlaxoSmithKline) was approved by FDA for the treatment of HIV infection in 1999. In 2003, Lexiva (fosamprenavir), a prodrug of amprenavir, was approved and is now the preferred form to extend the duration of available amprenavir and thus reducing the pill burden in patients. The antitumor activity of amprenavir has been validated in U87MG human glioblastoma cells (41) and Huh-7 hepatocarcinoma cells (42), and the mechanisms may involve the downregulation of vascular endothelial growth factor (VEGF) and hypoxia-inducible factor-1 (HIF-1) expression. Given the implications of ERK2 in the regulation of VEGF and HIF-1, it is reasonable to speculate that amprenavir may act by inhibiting ERK2-mediated angiogenesis and thus suppress tumor development. Additionally, a recent study revealed that amprenavir could blockage the activation of matrix metalloproteinase-2 (MMP-2) and inhibit the invasion of Huh-7 cells (42). Intriguingly, activation of ERK1/2 can contribute to the conversion of pro-MMP-2 to MMP-2 and then activate this enzyme (41). Therefore, inhibited ERK2-mediated activation of MMP-2 may also contribute to the antitumor effects of amprenavir.

Inhibited ERK1/2 activity may be implicated in the apoptotic cell death induced by several approved HIV-1 protease inhibitors. For example, inhibition of ERK1/2 signaling by ritonavir, nelfinavir and saquinavir could initiate growth arrest and apoptosis in human multiple myeloma cells (37), and a pro-apoptoptic action has been recorded in amprenavir-treated hepatocellular carcinoma xenograft models (42), though the accurate mechanisms remain unclear. Since phosphorylation of $\operatorname{Bim}_{\mathrm{EL}}$ Ser69 can enhance the proteosomal degradation of $\operatorname{Bim}_{\mathrm{EL}}(6)$ and reduce its binding to pro-survival molecules, such as Mcl-1, Bcl-xL and Bcl-2 (7), ERK2-mediated of Bim $\mathrm{EL}$ phosphorylation at Ser69 appears to be one of the critical modulators of its pro-apoptotic function. Intriguingly, a most recent research reported that in human mammary epithelial cancer cells including MCF-7 cells, expression levels of phosphorylated Bim $_{\mathrm{EL}}$ at Ser69 were elevated, and pro-survival proteins Bcl-xL and Mcl-1, who sequester Bim $\mathrm{EL}_{\mathrm{E}}$ in cancer cells, were also upregulated (5). Moreover, phosphorylation of $\mathrm{Bim}_{\mathrm{EL}}$ also participates in the apoptosis regulation in chronic lymphocytic leukemia (CLL) cells and thus is of great clinical significance in CLL (43). Our findings support a mechanism that amprenavir could induce apoptotic response in MCF-7 cells through the inhibition of ERK2-mediated Bim $_{\mathrm{EL}}$ phosphorylation at Ser69 (Fig. 7), suggesting the suppression of pro-survival, phosphorylated $\mathrm{Bim}_{\mathrm{EL}}$ as a potential strategy for anticancer therapeutics.

Animal study results confirmed the tumor growth inhibition and apoptosis induction effects of amprenavir in the in vivo settings (Figs. 8 and 9). As an approved drug, the pharmacokinetics of amprenavir has been extensively studied. According to the information available in FDA, for adults, its recommended capsule doses are $1,200 \mathrm{mg}$ twice daily; for patients $<13$ years of age or adolescents $<50 \mathrm{~kg}$, its recommended capsule dosage is $20 \mathrm{mg} / \mathrm{kg}$ ( $22.5 \mathrm{mg} / \mathrm{kg}$ for oral solution) twice daily or $15 \mathrm{mg} /$ $\mathrm{kg}(17 \mathrm{mg} / \mathrm{kg}$ for oral solution) 3 times a day to a maximum dose of 2,400 mg (2,800 $\mathrm{mg}$ for oral solution). In our in vivo study, we adopted a daily dose of $45 \mathrm{mg} / \mathrm{kg} / \mathrm{day}$, which is within the range of therapeutically recommended dosage of this drug. These results demonstrate that amprenavir is expected to be a promising anticancer drug under the established drug regimen. A most recent study has reported that the combination of amprenavir-doxorubicin could reach a significantly inhibitory effects of tumor growth earlier than the two drugs individually (42), suggesting the combined use of amprenavir and other chemotherapeutic agents as a potential strategy to increase antitumor efficacy and decrease chemoresistance.

In conclusion, in the present study, we in silico screened 1447 FDA-approved small molecule drugs against ERK2 and identified amprenavir as a potential inhibitor of ERK2. We confirmed its ability to inhibit ERK2 kinase activity and human MCF-7 breast cancer cell proliferation, elucidated its unique apoptosis-inducing mechanisms by inhibiting ERK2-mediated phosphorylation of $\mathrm{Bim}_{\mathrm{EL}}$ at Ser69, and validated its anti-proliferative and apoptosis-inducing effects in MCF-7 xenograft models. These findings suggest amprenavir as a novel modulator of ERK2 signaling pathway and provide insights into its antitumor activities and mechanisms in MCF-7 cells both in vitro and in vivo, which may reveal possible new uses of this drug in anticancer treatment and supply a paradigm of repositioning existing approved drugs for additional therapeutic uses.

\section{Acknowledgements}

This study was supported in part by the Sichuan Science Foundation (no. 2015JY0183), by Sichuan Health and Family Planning Commission Funding (16ZD0253), the Researcher Foundation of Sichuan Academy of Medical Science and Sichuan Provincial People's Hospital and Sichuan Scientific Research Foundation of the Returned Overseas Chinese Scholars. We are grateful to Rong Sun, Bin Zhang, Huailong Xu, Lei Wu, Na An and Nan Zhou (Sichuan University) for their kind help and useful suggestions on this manuscript.

\section{References}

1. Giacinti L, Claudio PP, Lopez M and Giordano A: Epigenetic information and estrogen receptor alpha expression in breast cancer. Oncologist 11: 1-8, 2006.

2. Siegel R, Naishadham D and Jemal A: Cancer statistics, 2013. CA Cancer J Clin 63: 11-30, 2013.

3. O'Connor L, Strasser A, O'Reilly LA, Hausmann G, Adams JM, Cory S and Huang DC: Bim: A novel member of the Bcl-2 family that promotes apoptosis. EMBO J 17: 384-395, 1998.

4. Akiyama T, Dass CR and Choong PF: Bim-targeted cancer therapy: A link between drug action and underlying molecular changes. Mol Cancer Ther 8: 3173-3180, 2009.

5. Gogada R, Yadav N, Liu J, Tang S, Zhang D, Schneider A Seshadri A, Sun L, Aldaz CM, Tang DG, et al: Bim, a proapoptotic protein, up-regulated via transcription factor E2F1-dependent mechanism, functions as a prosurvival molecule in cancer. J Biol Chem 288: 368-381, 2013.

6. Luciano F, Jacquel A, Colosetti P, Herrant M, Cagnol S, Pages G and Auberger P: Phosphorylation of Bim-EL by Erk1/2 on serine 69 promotes its degradation via the proteasome pathway and regulates its proapoptotic function. Oncogene 22: 6785-6793, 2003.

7. Ewings KE, Hadfield-Moorhouse K, Wiggins CM, Wickenden JA, Balmanno K, Gilley R, Degenhardt K, White E and Cook SJ: ERK1/2-dependent phosphorylation of BimEL promotes its rapid dissociation from Mcl-1 and Bcl-xL. EMBO J 26: 2856-2867, 2007. 
8. Zhang H, Qian DZ, Tan YS, Lee K, Gao P, Ren YR, Rey S, Hammers H, Chang D, Pili R, et al: Digoxin and other cardiac glycosides inhibit HIF-1alpha synthesis and block tumor growth. Proc Natl Acad Sci USA 105: 19579-19586, 2008.

9. Miller SC, Huang R, Sakamuru S, Shukla SJ, Attene-Ramos MS, Shinn P, Van Leer D, Leister W, Austin CP and Xia M: Identification of known drugs that act as inhibitors of NF-kappaB signaling and their mechanism of action. Biochem Pharmacol 79: 1272-1280, 2010.

10. Biechele TL, Camp ND, Fass DM, Kulikauskas RM, Robin NC, White BD, Taraska CM, Moore EC, Muster J, Karmacharya R, et al: Chemical-genetic screen identifies riluzole as an enhancer of Wnt/ $\beta$-catenin signaling in melanoma. Chem Biol 17: $1177-1182,2010$

11. Dudley JT, Deshpande T and Butte AJ: Exploiting drug-disease relationships for computational drug repositioning. Brief Bioinform 12: 303-311, 2011.

12. Okimoto N, Futatsugi N, Fuji H, Suenaga A, Morimoto G, Yanai R, Ohno Y, Narumi T and Taiji M: High-performance drug discovery: Computational screening by combining docking and molecular dynamics simulations. PLoS Comput Biol 5: e1000528, 2009.

13. Kinoshita T, Yoshida I, Nakae S, Okita K, Gouda M, Matsubara M, Yokota K, Ishiguro $\mathrm{H}$ and Tada T: Crystal structure of human mono-phosphorylated ERK1 at Tyr204. Biochem Biophys Res Commun 377: 1123-1127, 2008.

14. Aronov AM, Baker C, Bemis GW, Cao J, Chen G, Ford PJ, Germann UA, Green J, Hale MR, Jacobs M, et al: Flipped out: Structure-guided design of selective pyrazolylpyrrole ERK inhibitors. J Med Chem 50: 1280-1287, 2007.

15. Rose PW, Bi C, Bluhm WF, Christie CH, Dimitropoulos D, Dutta S, Green RK, Goodsell DS, Prlic A, Quesada M, et al: The RCSB Protein Data Bank: New resources for research and education. Nucleic Acids Res 41: D475-D482, 2013.

16. Pettersen EF, Goddard TD, Huang CC, Couch GS, Greenblatt DM, Meng EC and Ferrin TE: UCSF Chimera - a visualization system for exploratory research and analysis. J Comput Chem 25: $1605-1612,2004$.

17. Kuntz ID, Blaney JM, Oatley SJ, Langridge R and Ferrin TE: A geometric approach to macromolecule-ligand interactions. J Mol Biol 161: 269-288, 1982.

18. Knox C, Law V, Jewison T, Liu P, Ly S, Frolkis A, Pon A, Banco K, Mak C, Neveu V, et al: DrugBank 3.0: A comprehensive resource for 'omics' research on drugs. Nucleic Acids Res 39: D1035-D1041, 2011.

19. O'Boyle NM, Banck M, James CA, Morley C, Vandermeersch T and Hutchison GR: Open Babel: An open chemical toolbox. J Cheminform 3: 33, 2011.

20. Irwin JJ, Sterling T, Mysinger MM, Bolstad ES and Coleman RG: ZINC: A free tool to discover chemistry for biology. J Chem Inf Model 52: 1757-1768, 2012.

21. Lang PT, Brozell SR, Mukherjee S, Pettersen EF, Meng EC, Thomas V, Rizzo RC, Case DA, James TL and Kuntz ID: DOCK 6: Combining techniques to model RNA-small molecule complexes. RNA 15: 1219-1230, 2009.

22. Van Der Spoel D, Lindahl E, Hess B, Groenhof G, Mark AE and Berendsen HJ: GROMACS: Fast, flexible, and free. J Comput Chem 26: 1701-1718, 2005.

23. Schüttelkopf AW and van Aalten DM: PRODRG: A tool for highthroughput crystallography of protein-ligand complexes. Acta Crystallogr D Biol Crystallogr 60: 1355-1363, 2004.

24. Li C, Chen J, Lu B, Shi Z, Wang H, Zhang B, Zhao K, Qi W, Bao J and Wang Y: Molecular switch role of Akt in Polygonatum odoratum lectin-induced apoptosis and autophagy in human non-small cell lung cancer A549 cells. PLoS One 9: e101526, 2014.

25. Shi W, Deng J, Tong R, Yang Y, He X, Lv J, Wang H, Deng S, Qi P, Zhang D, et al: Molecular mechanisms underlying mangiferininduced apoptosis and cell cycle arrest in A549 human lung carcinoma cells. Mol Med Rep 13: 3423-3432, 2016

26. Wang Y, Liu Y, Wang H, Li C, Qi P and Bao J: Agaricus bisporus lectins mediates islet $\beta$-cell proliferation through regulation of cell cycle proteins. Exp Biol Med (Maywood) 237: 287-296, 2012
27. Jiagang D, Li C, Wang H, Hao E, Du Z, Bao C, Lv J and Wang Y: Amygdalin mediates relieved atherosclerosis in apolipoprotein $\mathrm{E}$ deficient mice through the induction of regulatory $\mathrm{T}$ cells. Biochem Biophys Res Commun 411: 523-529, 2011.

28. Yang W, Zheng Y, Xia Y, Ji H, Chen X, Guo F, Lyssiotis CA, Aldape K, Cantley LC and Lu Z: ERK1/2-dependent phosphorylation and nuclear translocation of PKM2 promotes the Warburg effect. Nat Cell Biol 14: 1295-1304, 2012.

29. Wang Y, Wang H, Liu Y, Li C, Qi P and Bao J: Antihyperglycemic effect of ginsenoside Rh2 by inducing islet beta-cell regeneration in mice. Horm Metab Res 44: 33-40, 2012.

30. Yun J, Lv YG, Yao Q, Wang L, Li YP and Yi J: Wortmannin inhibits proliferation and induces apoptosis of MCF-7 breast cancer cells. Eur J Gynaecol Oncol 33: 367-369, 2012.

31. He JC, Husain M, Sunamoto M, D'Agati VD, Klotman ME, Iyengar R and Klotman PE: Nef stimulates proliferation of glomerular podocytes through activation of Src-dependent Stat3 and MAPK1,2 pathways. J Clin Invest 114: 643-651, 2004.

32. Biggs TE, Cooke SJ, Barton CH, Harris MP, Saksela K and Mann DA: Induction of activator protein 1 (AP-1) in macrophages by human immunodeficiency virus type-1 NEF is a cell-typespecific response that requires both hck and MAPK signaling events. J Mol Biol 290: 21-35, 1999.

33. Schrager JA, Der Minassian V and Marsh JW: HIV Nef increases T cell ERK MAP kinase activity. J Biol Chem 277: 6137-6142, 2002.

34. Kinoshita T, Warizaya M, Ohori M, Sato K, Neya M and Fujii T: Crystal structure of human ERK2 complexed with a pyrazolo[3,4-c]pyridazine derivative. Bioorg Med Chem Lett 16: 55-58, 2006.

35. Park H, Bahn YJ, Jeong DG, Woo EJ, Kwon JS and Ryu SE: Identification of novel inhibitors of extracellular signal-regulated kinase 2 based on the structure-based virtual screening. Bioorg Med Chem Lett 18: 5372-5376, 2008.

36. Ohori M, Kinoshita T, Okubo M, Sato K, Yamazaki A, Arakawa H, Nishimura S, Inamura N, Nakajima H, Neya M, et al: Identification of a selective ERK inhibitor and structural determination of the inhibitor-ERK2 complex. Biochem Biophys Res Commun 336: 357-363, 2005.

37. Aronov AM, Tang Q, Martinez-Botella G, Bemis GW, Cao J, Chen G, Ewing NP, Ford PJ, Germann UA, Green J, et al: Structure-guided design of potent and selective pyrimidylpyrrole inhibitors of extracellular signal-regulated kinase (ERK) using conformational control. J Med Chem 52: 6362-6368, 2009.

38. Wang Z, Canagarajah BJ, Boehm JC, Kassisà S, Cobb MH, Young PR, Abdel-Meguid S, Adams JL and Goldsmith EJ: Structural basis of inhibitor selectivity in MAP kinases. Structure 6: 1117-1128, 1998

39. Ikezoe T, Saito T, Bandobashi K, Yang Y, Koeffler HP and Taguchi H: HIV-1 protease inhibitor induces growth arrest and apoptosis of human multiple myeloma cells via inactivation of signal transducer and activator of transcription 3 and extracellular signal-regulated kinase 1/2. Mol Cancer Ther 3: 473-479, 2004.

40. Pyrko P, Kardosh A, Wang W, Xiong W, Schönthal AH and Chen TC: HIV-1 protease inhibitors nelfinavir and atazanavir induce malignant glioma death by triggering endoplasmic reticulum stress. Cancer Res 67: 10920-10928, 2007.

41. Pajonk F, Himmelsbach J, Riess K, Sommer A and McBride WH: The human immunodeficiency virus (HIV)-1 protease inhibitor saquinavir inhibits proteasome function and causes apoptosis and radiosensitization in non-HIV-associated human cancer cells. Cancer Res 62: 5230-5235, 2002.

42. Gills JJ1, Lopiccolo J, Tsurutani J, Shoemaker RH, Best CJ, Abu-Asab MS, Borojerdi J, Warfel NA, Gardner ER, Danish M, et al: Nelfinavir, A lead HIV protease inhibitor, is a broadspectrum, anticancer agent that induces endoplasmic reticulum stress, autophagy, and apoptosis in vitro and in vivo. Clin Cancer Res 13: 5183-5194, 2007.

43. Esposito V, Verdina A, Manente L, Spugnini EP, Viglietti R, Parrella R, Pagliano P, Parrella G, Galati R, De Luca A, et al: Amprenavir inhibits the migration in human hepatocarcinoma cell and the growth of xenografts. J Cell Physiol 228: 640-645, 2013. 